\title{
Modeling Slope Topography Using Unmanned Aerial Vehicle Image Technique
}

\author{
Fu-Hsuan Yeh ${ }^{1, *}$, Chun-Jia Huang ${ }^{1}$, Jen-Yu $\operatorname{Han}^{1}$, and Louis Ge ${ }^{1}$ \\ ${ }^{1}$ Department of Civil Engineering, National Taiwan University, 10617 Taipei, Taiwan
}

\begin{abstract}
Nowadays, a wide range of site planning, field investigation and slope analysis need to be carried out for slope protection and landslide-related disaster reduction. To enhance the efficiency of topography modeling, unmanned aerial vehicle (UAV) has become a new surveying technique to obtain spatial information. This study aims to determine the topography of a slope by using a digital camera mounted on UAV to photograph with a high degree of overlap. The 3D point clouds data were generated through image feature point extraction integrated with accurate GPS ground control points. It is found in this study that the obtained Digital Surface Model (DSM) data, compared with the traditional field surveying techniques, has much superior performance. The resolution of the DSM has reached $1.58 \mathrm{~cm}$. Also, the error of elevation and distance between DSM and actual 3D coordinates obtained by traditional total station survey is acceptance. It is clear that such a UAV surveying technique can replace conventional surveying methods and provide complete and accurate 3D topography information in automatic and highly efficient manner for most geotechnical applications.
\end{abstract}

\section{Introduction}

Recently, unmanned aerial vehicle (UAV) has become a new surveying technique to obtain spatial information. Many researches have been focusing on applying UAVs to cope with disasters and acquire three-dimensional (3D) mapping and modeling. For example, Turner et al. [1] have compared their UAV mapping with those obtained by traditional aerial or satellite platforms. It was concluded that UAV-acquired datasets have better resolutions in both temporal and spatial aspects. For typical mapping tasks, their geometry and associated attributes should be identified and corrected first. Laliberte and Rango [2] mapped a land cover of an experimental range in New Mexico, USA. Wallace et al. [3] conducted forest inventory in the University of Tasmania in Australia. Lucieer et al. [4] and Turner et al. [5] mapped and monitored moss beds in the Antarctic area. Remondino et al. [6] concluded that 3D results like $\mathrm{DSM} / \mathrm{DTM}$, contour lines, textures 3D models, vector data, can be produced in a reasonable automated way by using UAV platforms. Abdelkader et al. [7] conducted real-time flash-flood monitoring in the Jeddah hydrological basin in Saudi Arabia. Siebert and Teizer [8] built a UAV system to rapidly and autonomously acquire mobile 3D mapping data. Goncalves and Henriques [9] used a UAV to map and monitor sand dunes and beaches in sensitive coastal areas. Liu et al. [10] collected information, including the potential applications of UAV to seismic risk assessment, transportation, disaster response, construction management, surveying and mapping, and flood monitoring and assessment. It can be seen that the above-mentioned environmental applications have been used in broad areas. More applications of various kinds can be expected in the near future.

In Taiwan, rock fall is a common geo-disaster that threatens people's properties and lives. The survey area is a slope land near the Qingshui cliff, located in Xiulin Township, Hualien County, in eastern Taiwan, where a railway track is passing by (see Fig.1). The survey area is about 0.29 ha. For the sake of slope protection and train safety, a rock-fall protection fence, named ultra-light fence, is planned to build along the slope. Before planning and design, topographic surveys need to be carried out to evaluate the site condition and suitability of the survey area. Therefore, it was accomplished by gathering spatial information including elevations and surface features of the surrounding terrain. To enhance the efficiency of topography modeling, unmanned aerial vehicle (UAV) has become a popular surveying technique to acquire spatial information. Data for orthophotos, 3D models, and point clouds in high density with great accuracy can be obtained. By using the information, any slope's cross section can be plotted for further design.

In addition, the conventional method, where the spatial information is obtained from a total station, is carried out in this case. The goal of this paper is to evaluate the UAV technique in comparison with the conventional method, and assess the difference between the both methods.

\footnotetext{
* Corresponding author: stillya81@gmail.com
} 


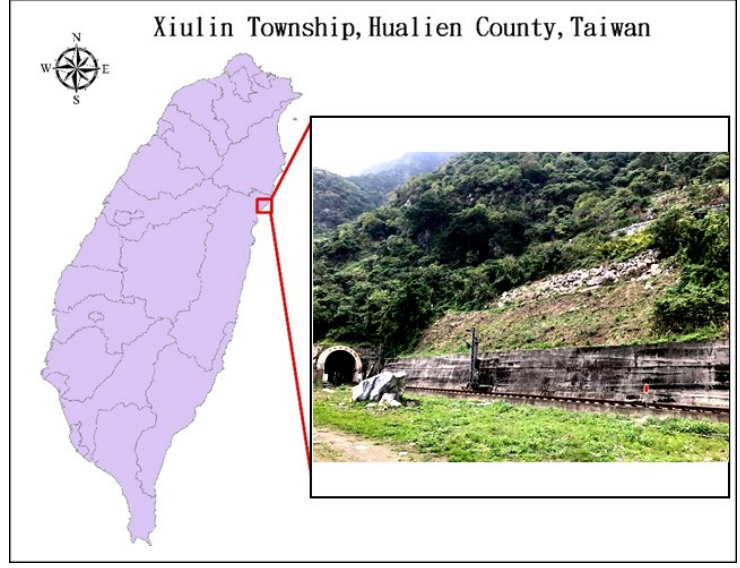

Fig.1. The condition of the survey area

\section{Methodology}

Fig. 2 shows the procedure of the method to obtain the slope topographic information by using UAV images. Firstly, flight route plan should be developed and ground control points should be preselected for preparation. Hardware and flight controller of the UAV system, including aircraft structure, battery, sensors and signal, need to be checked.

Afterwards, the flight route and surrounding environment are examined. The quadrocoper can be turned on, where the flight planning is ready to start. After the quadrocoper takes off, it will follow the operator's instruction and take photos. When the expected flight planning is finished, the UAV returns automatically to its lift-off location by switching "coming home" mode or being manually operated by the operator. If the survey cannot be performed in one trip, additional flights can be carried out. It is noted that the flying height should remain the same, so as to ensure the images that can be merged seamlessly.

Additionally, GPS control survey should be conducted before or after the UAV work finished. After that, these images can be post-processed using photogrammetry technique, where the spaitial information can be generated. Pix4Dmapper Pro is software uses the photo-grammetry technique. It is customizable, timely, and can complement a wide range of applications. It can turn images into geo-referenced 2D maps and 3D models with high precisions. The UAV images, therefore, can be processed by using this analysis software.

\subsection{Definition of UAV system}

UAV is an aircraft without a human pilot aboard. The DJI Phantom 4 was used in this work. Shown in Fig.3, the UAV is approximately $1380-\mathrm{g}$ in weight, consisting of four light flying wings, frame structure, multiple sensors (including GPS, gyroscope, barometer and accelerometer), high performance camera, an advanced 3axis gimbal with flight controller and telemetry control system. The UAV camera has a 12-Megapixel $(4000 \times 3000$ pixels $)$ sensor. Table 1 shows the detailed specification for DJI Phantom 4.
DJI Phantom 4 is capable of staying up in the air for about 28 minutes and can fly around $5 \mathrm{~km}$ of range, with complete control and a live 720p HD view of everything the camera sees. In this case, the surveying assignments of the operational altitude was about $30 \mathrm{~m}$. In a flight with an overlap more than $80 \%, 198$ photos were obtained for further analysis. The spatial resolution was about 1.58 $\mathrm{cm} /$ pixel (see Table 2).

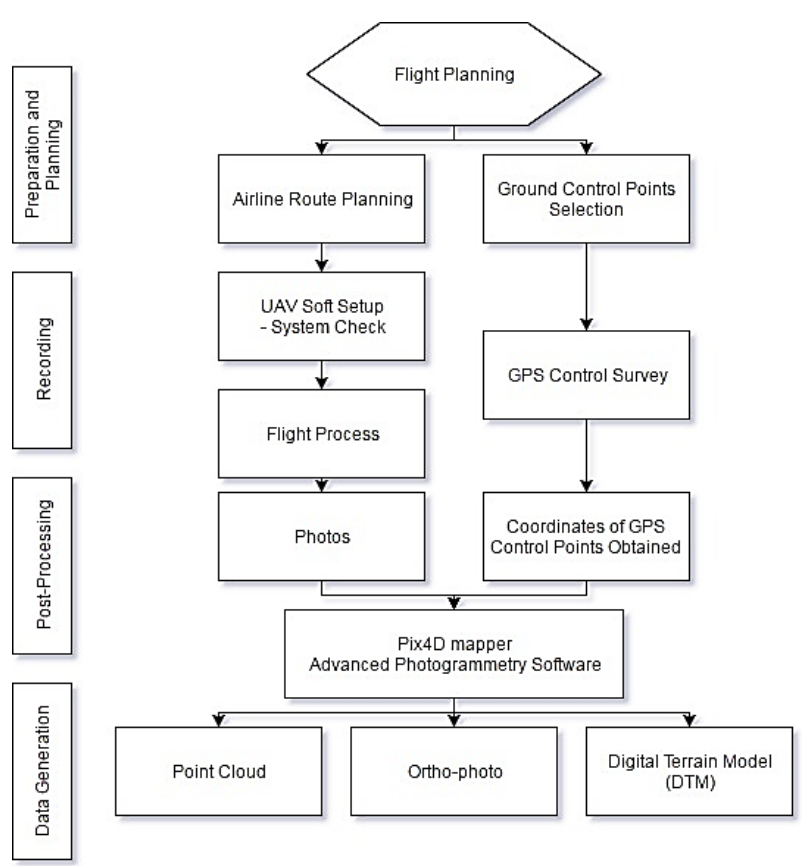

Fig.2. UAV flight methodology: preparation, recording, post-flight data processing, and data generation

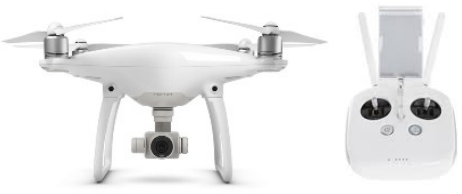

Fig.3. DJI Phantom 4

Table 1. Specification of DJI Phantom 4

\begin{tabular}{|c|c|c|c|}
\hline Item & Content & Item & Content \\
\hline $\begin{array}{c}\text { Effective } \\
\text { pixels }\end{array}$ & $\begin{array}{c}12 \\
\text { Megapixels }\end{array}$ & Image size & $4000 \times 3000$ \\
\hline Len & $\begin{array}{c}\text { FOV94 } 20 \\
\mathrm{~mm}\end{array}$ & $\begin{array}{c}\text { Flight } \\
\text { weight }\end{array}$ & $1380 \mathrm{~g}$ \\
\hline Sensor & $\begin{array}{c}1 / 2.3 \\
\text { CMOS }\end{array}$ & $\begin{array}{c}\text { Diagonal } \\
\text { Size } \\
\text { (Propellers } \\
\text { Excluded) }\end{array}$ & $350 \mathrm{~mm}$ \\
\hline
\end{tabular}


Table 2. The information of operation

\begin{tabular}{|c|c|}
\hline Item & Content \\
\hline Flight height $(\mathrm{m})$ & 30 \\
\hline Number of shots & 198 \\
\hline $\begin{array}{c}\text { Spatial resolution }(\mathrm{cm} / \\
\text { pixel) }\end{array}$ & 1.58 \\
\hline
\end{tabular}

\subsection{Total Station}

Pentax-R202NE was set up for the sake of comparing with the UAV technique. It is a surveying equipment combining Electromagnetic Distance Measuring Instrument and electronic theodolite. The instrument can be used to measure horizontal and vertical angles as well as sloping distance of object to the instrument, and collect all the necessary spatial information of points without using a prism or a pole. The accuracy of distance measurement is $3 \mathrm{~mm}+2 \mathrm{ppm}$. The accuracy of angle measurement varies from 2 to 6 seconds.

\subsection{Aerial Triangulation}

This paper uses the UAV image to obtain the object space coordinates of tirrena. The method incoporates the aerial triangulation theory. The aerial Triangulation in Photogrammetry is a method determining and calculating 3D object coordinates by using photographs exposed from different positions, covering the same object. With aerial triangulation in aerial photogrammetry, it might be able to calculate 3D coordinates for object elements on almost any object (see Fig.4). It needs at least three ground control points with known positions that are visible in at least some of the photos. The ground control points have to be a part of the aerial triangulation (e.g. Hamid [11]).

The calculation method uses rigorous collinearity equations in photogrammetry to establish the object-UAV image relationship. In addition, the lens distortion needs to be considered. The UAV camera must be rigorously calibrated. Equation (1) uses to calculate a space intersection, with known interior orientation parameters of a camera. In equation (1), x, y are the image points, and $\mathrm{f}$ is the focal length. $\Delta x, \Delta y$ denote the camera calibration parameters. The external orientation parameters, $X_{L}, Y_{L}, Z_{L}$, are the perspective center coordinates, while $m_{11}$ to $m_{13}$ are rotation matrix coefficients. The unknowns are the object space coordinates $\left(X_{L}, Y_{L}, Z_{L}\right)$ to which image points correspond (Mikhail [12]).

Therefore, the $3 \mathrm{D}$ object coordinates are calculated by using the spatial intersections. Finally, the image dense matching is used to generate 3D point clouds and Digital Surface Model (DSM).

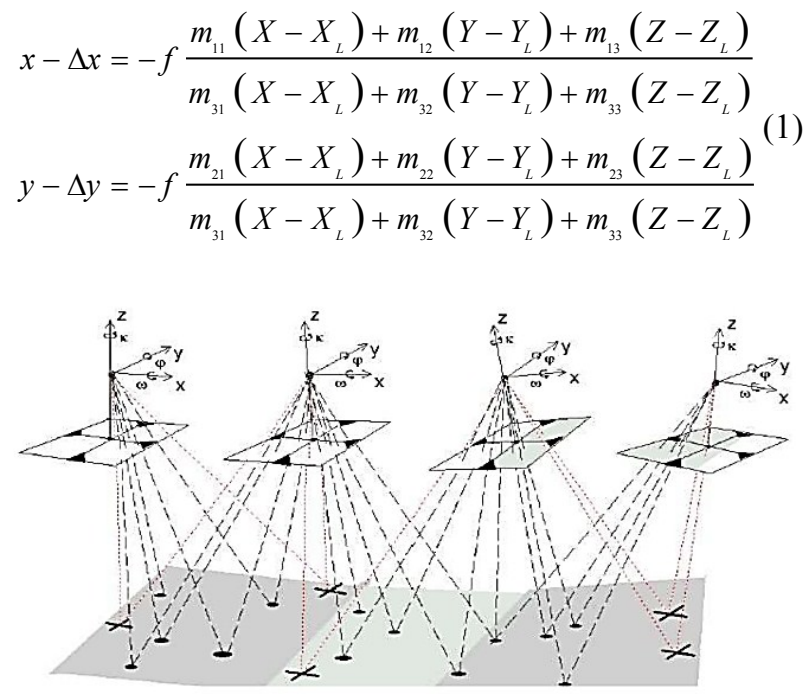

Fig.4. Aerial triangulation (wolf [13])

\subsubsection{Ground control survey}

If UAV system is used for surveying work, global positioning system (GPS) control points need to be set up for acquiring data with high precision. These control points are set manually before the UAV flies and are created for generating a Geographic coordinate system (Taiwan Datum 1997). They are used to correct the image orientation. In the survey area covered by natural features, it is not appropriate to use trees and rocks as control points; therefore, artificial points needed to be placed on the ground surface. The man-made features should be sufficiently clear and fixed carefully to avoid being damaged before GPS operation and UAV photographing. A minimum of three ground control points are required, so in this study, four ground control points were set up with a uniform distribution (see Fig.5).
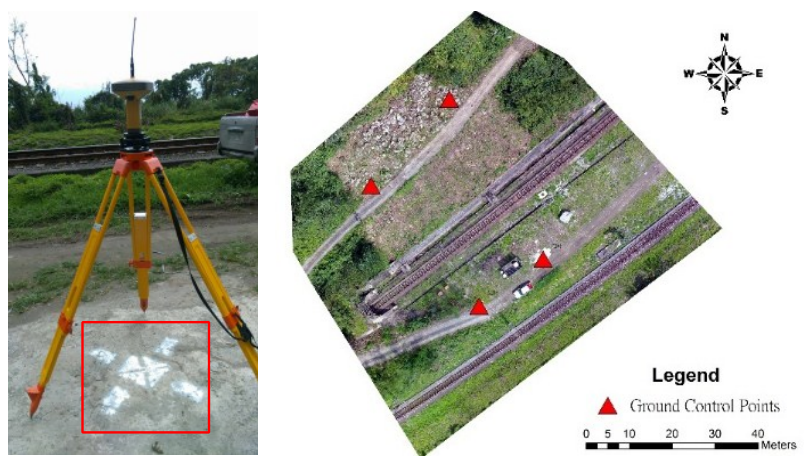

Fig.5. Distribution of GPS control points

\section{Result and Analysis}

\subsection{Photogrammetric data processing}

The data processing is simple. All aerial images from UAV need to be imported from camera to computer. It is very important that the images have adequate overlaps between each other. Also, the 3D coordinates of GPS should be applied in the program. In this study, the 
Average Ground Sampling Distance (GSD), which is also called spatial resolution, the distance between pixel centers as measured on the ground, was approximately $1.58 \mathrm{~cm}$. The analysis result shows that these images are sufficient for good quality matching.

It is essential to export the results as $3 \mathrm{D}$ colored point clouds or orthophotos, as shown in Fig.6 and Fig.7, respectively. Fig. 8 shows the DSM, which is generated by 3D point clouds, represents the MSL elevations of the reflective surfaces. The terrain profiles can be obtained from the DSM data. DSM data can be used for producing relief maps and be useful for surface terrain modeling, dip direction and angle inclination of slope, and any visualization applications. The topographic map contour lines can be automatically drawn by using DSM data as well.

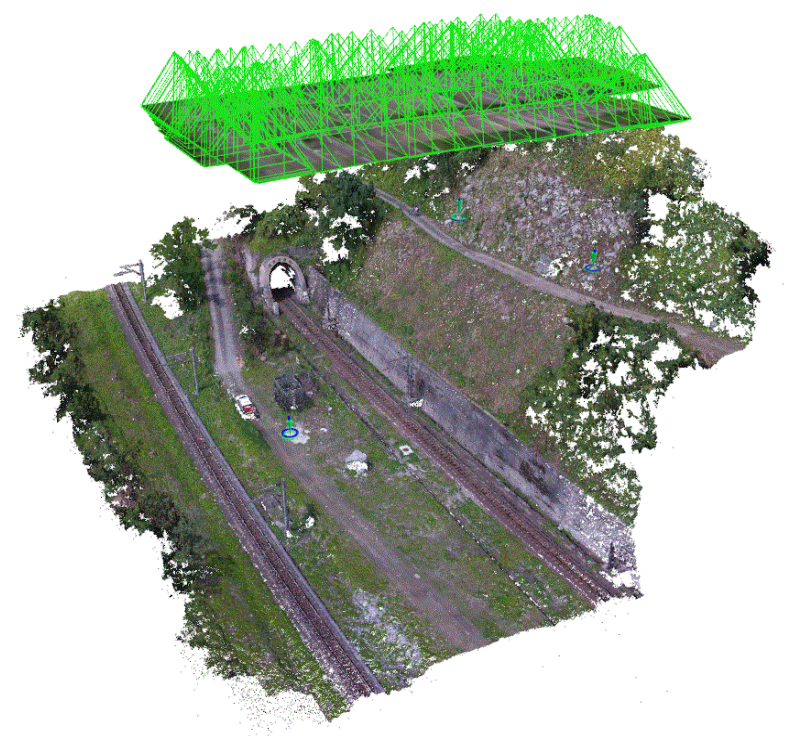

Fig.6. Point cloud generation in Pix4D

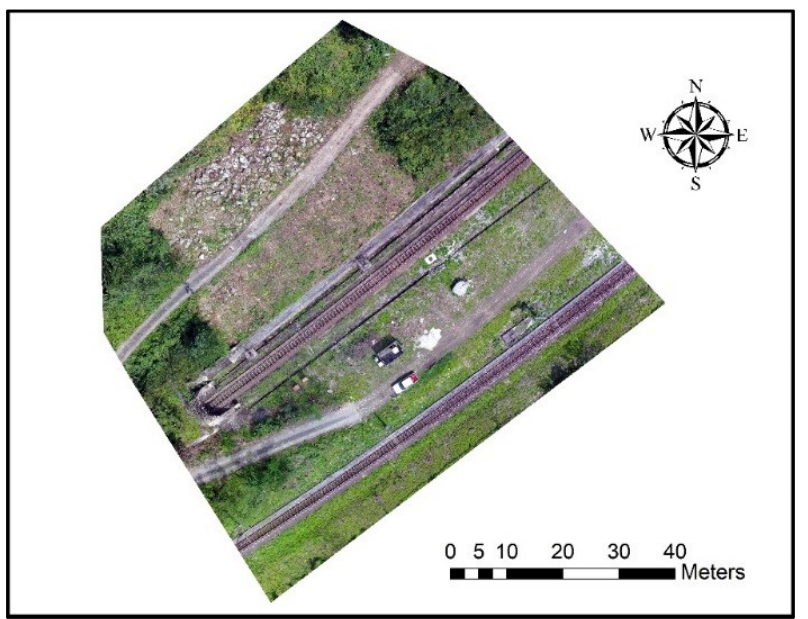

Fig.7. Orthophoto generation from Pix4D

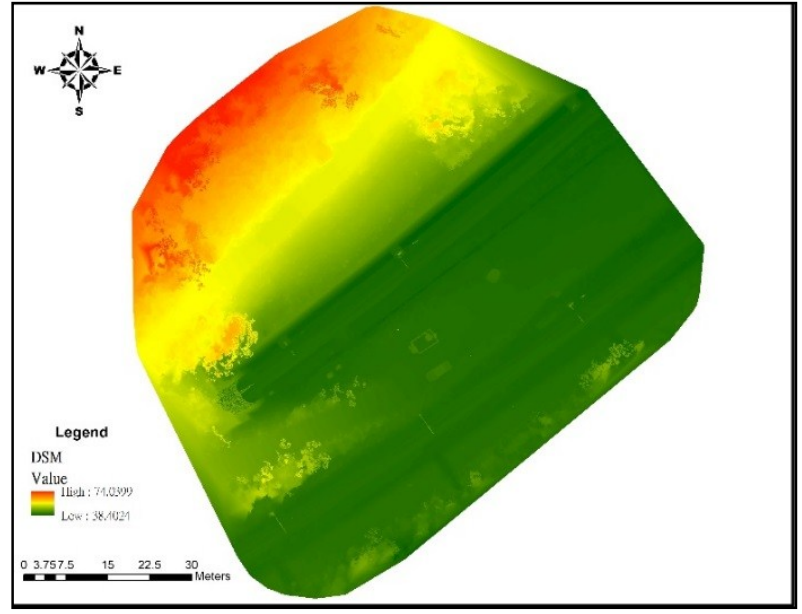

Fig.8. Digital surface model (DSM)

\subsection{Comparison with UAV Technique and Total Station}

In order to compare the pros and cons between UAV technique and total station, the results from both methods are presented in the following section. Fig.9 shows the three terrain profiles for comparison.

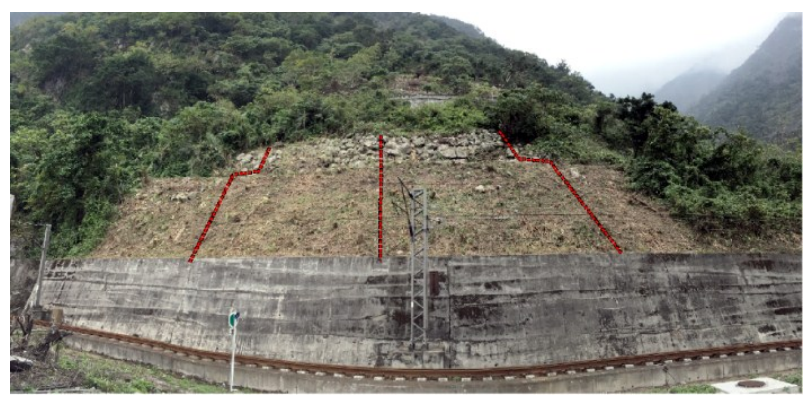

Fig.9. Terrain profile of the slope

\subsubsection{Terrain profile survey with Total Station}

The terrain profiles can be surveyed by using total station. A measuring line and sight along the line were selected. When a target is sighted, horizontal angles, zenith angle as well as horizontal distances are measured and recorded by surveyors accordingly. After obtaining the field data by the total station, the data, such as geographic coordinate system and elevation, can be processed in office.

\subsubsection{Terrain profile survey with UAV Data}

The terrain profiles from UAV data can be generated by the DSM information, as refer to 3.1 However, surface vegetation is filtered out by manual editing. The Digital Elevation Model can be generated after this procedure. The result is shown in Fig.10. 


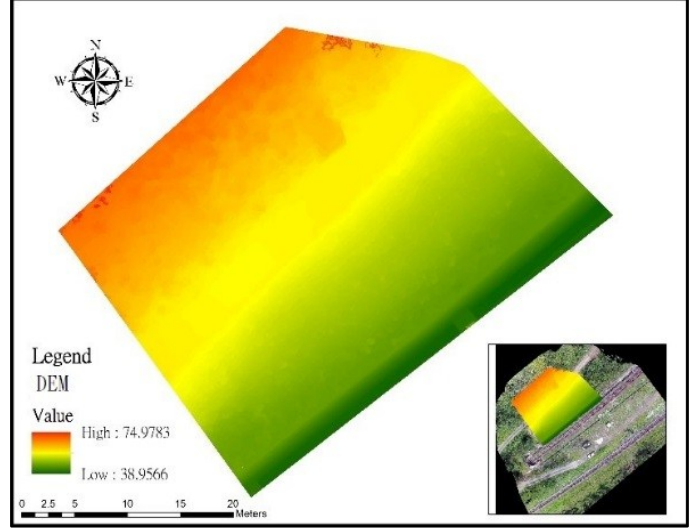

Fig.10. Digital Elevation model (DEM)

\subsubsection{Comparison of Terrain Results}

Table 3 shows the results of the terrain from the total station and UAV. The obtained spatial information from UAV is more complete than total station. In the field work, time spent and manpower for UAV technique are less than that for total station method. In general, the advantages of using total stations are "good accuracy of measurement" and "manual errors involved in reading and recording are eliminated". The disadvantages of using total stations are getting high cost and taking longer time and vice versa. Taking the total station as a reference, the maximum error of UAV result is $0.151 \mathrm{~m}$ and minimum error is $0.008 \mathrm{~m}$. There is $0.061 \mathrm{~m}$ root-mean-square error between the elevation results of UAV and total station. In this study, centimeter error variance is sufficient for this slope survey application. Fig.11 shows the terrain results from the UAV technique and total station method. It can be seen that the results of the two method are very close. In addition, UAV technique can capture more information as detailed as possible.

Table 3. Comparison terrain results between total station and UAV

\begin{tabular}{|c|c|c|c|}
\hline Method & $\begin{array}{c}\text { Quantities } \\
\text { (points) }\end{array}$ & $\begin{array}{c}\text { Time period } \\
\text { of field } \\
\text { work }\end{array}$ & Manpower \\
\hline $\begin{array}{c}\text { Total } \\
\text { Station }\end{array}$ & 50 & 3 hours & $2 \sim 3$ \\
\hline UAV & 3000 & 20 min & 1 \\
\hline
\end{tabular}

\begin{tabular}{|c|c|c|c|}
\hline \multirow{2}{*}{ Method } & $\begin{array}{c}\text { maximum } \\
\text { error }\end{array}$ & $\begin{array}{c}\text { minimum } \\
\text { error }\end{array}$ & $\begin{array}{c}\text { Root-mean- } \\
\text { square error }\end{array}$ \\
\cline { 2 - 4 } & $(\mathrm{m})$ & $(\mathrm{m})$ & $(\mathrm{m})$ \\
\hline $\begin{array}{c}\text { Total } \\
\text { Station }\end{array}$ & - & - & - \\
\hline UAV & 0.151 & 0.008 & 0.061 \\
\hline
\end{tabular}
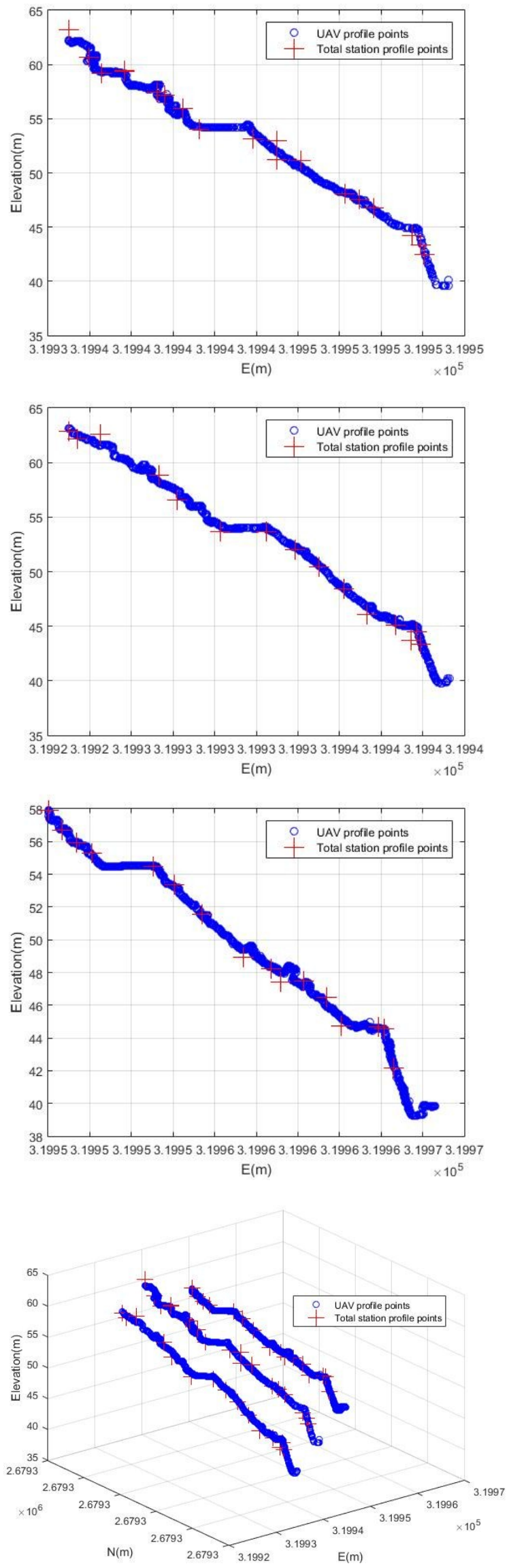

Fig.11. Comparison terrain results between total station and UAV 


\section{Conclusion}

Generally, the conventional surveying technique, the total station method, can collect information more accurately but needs much more time, money and operating skill. In this study, the conventional method with the total station and UAV methods were compared and evaluated. The result shows that there is $0.061 \mathrm{~m}$ root-mean-square error between the elevation results of UAV and total station. In such slope survey for site condition evaluation and design, centimeter error variance is acceptable.

Using the UAV technology not only obtains highspatial-resolution observations and contribute a new version for constructing high-fidelity $3 \mathrm{D}$ models, but also gets low operating costs. It is more efficient to generate the topographic maps completely. It provides many opportunities in civil engineering applications.

\section{References}

1. Turner, D., Lucieer, A. and Wallace, L., IEEE Trans. Geosci. Remote Sens., 52(5), 2738-2745 (2013).

2. Laliberte, A.S and Rango, A., IEEE T. Geosci. Remote Sens., 47(3), 761-770 (2009).

3. Wallace, L., Lucieer, A., Watson, C. and Turner, D., Remote Sensing, 4(6), 1519-1543 (2012).

4. Lucieer, A, Robinson, S. and Turner, D.J., Proceedings of the 34th International Symposium on Remote Sensing of Environment (ISRSE34, 2011).

5. Turner, D., Lucieer, A. and Watson, C., Remote Sensing, 4(5), 1392-1410 (2012).

6. Remondino, F., Barazzetti, L., Nex, F., Scaioni, M. and Sarazzi, D., Remote Sensing and Spatial Information Sciences, 38(1/C22) (ISPRS ICWG I/V, 2011).

7. Abdelkader, M., Shaqura, M., Claudel, C.G. and Gueaieb, W., Proceedings of the 2013 International Conference on Unmanned Aircraft Systems (2013).

8. Siebert, S. and Teizer, J., Automation in Construction, 41, 1-14 (2014).

9. Gonçalves, J.A. and Henriques, R., ISPRS P\&RS, 104, 101-111 (2015).

10. Liu, P., Chen, A.Y., Huang, Y.N., Han, J.Y., Lai, J.S., Kang, S.C., Wu, T.H., Wen, M.C. and Tsai, M.H., Smart Struct. Syst., 13(6), 1065-1094 (2014).

11. Hamid, E., Advanced Analytical Aerial Triangulation, 1nd ed. (K.N.Toosi, Unversity of Technology, 2006)

12. Mikhail, E.M., James, S. B. and McGlone, J. C., Introduction to modern photogrammetry, lnd ed. (Wiley, 2001)

13. Wolf, P.R. and Dewitt, B.A., Elements of Photogrammetry with Applications in GIS, 3nd ed. (McGraw-Hill, 2000). 